\title{
STRENGTH AND ABRASION RESISTANCE OF RECYCLED LEAD SLAG MORTAR AT HIGH TEMPERATURES
}

\author{
M. H. Seleem \\ Materials Engineering Department, Zagazig University, Zagazig, Egypt.
}

\begin{abstract}
The effect of high termperatures on the compressive strength and abrasion resistance of mortar fabricated by using lead slag extracted from recycling of the spent batteries in the homely workshops as fine aggregates was experimentally investigated. The fine lead slag (FLS) was used as a partial replacement of the total fine aggregate (TFA), sand, by different percentages of volume (FLS/TFA $=0,10,20,30$ and 40\%). Test specimens were subjected to high temperatures ranging from $200^{\circ} \mathrm{C}$ to $700^{\circ} \mathrm{C}$ step $100^{\circ} \mathrm{C}$. The exposure time after reaching the desired target temperature kept at two hours. The sequence of the residual unstressed test was followed. The weight loss and the relative compressive strength (strength of heated specimen to that of the corresponding unheated specimen) were determined. The weight loss of the heated and unheated specimens due to exposure to abrasive wear was also calculated. Test results indicated that, at certain FLS/TFA\%, the relative compressive strength decreased gradually with high temperature up to $500^{\circ} \mathrm{C}$ and after that it showed a sudden drop with further increases in temperature. The abrasion resistance decreased with increasing high temperature. The compressive strength and abrasion resistance of mortar increased up to replacement of $20 \%$ of sand by FLS and after that it decreased but still higher than that of $100 \%$ sand. Both compressive strength and abrasion resistance of FLS mortar relative to those of $100 \%$ sand enhanced clearly with the presence of FLS at temperature above" $500^{\circ} \mathrm{C}$

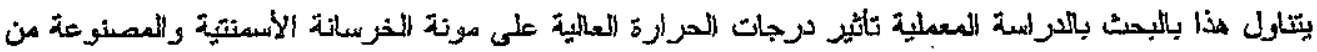

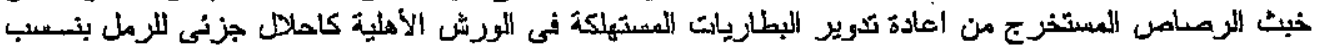

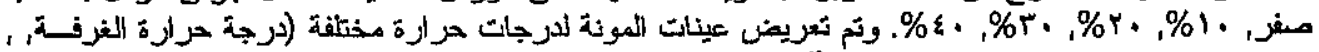

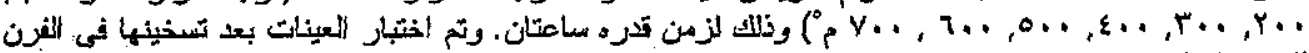

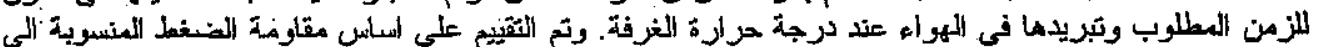

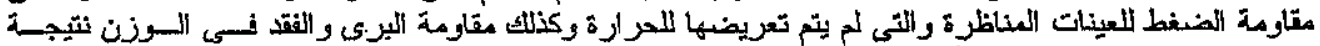

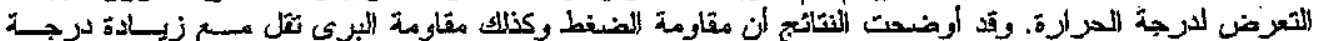

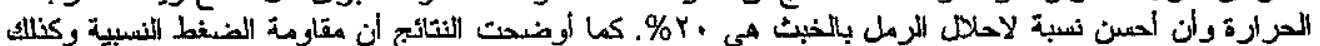

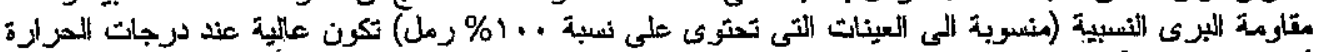

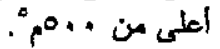

Keywords: Recycled lead-slag; Mortar; High temperature; Compressive strength; Abrasion resistance.

\section{INTRODUCTION}

The high consumption of natural sources, the high amount of industrial wastes and environmental pollution require new solutions for a sustainable development. One of the major contributions to the preservation of the environment and sustainable development is the reuse and recycling of the waste materials. Use of inorganic industrial residual products in making cementations products as concrete and mortar will lead to sustainable concrete design and a greener environment [1].

The need to develop concrete and mortar with nonconventional aggregates is urgent for environmental as werl as economic reasons. A review of earlier research showed that industrial as well as other wastes have been used in concrete-making to improve the properties of concrete and to reduce cost. Inclusion of recycled tire rubber fibers in concrete was found to avoid the opening of cracks and increase energy absorption [2]. Structural light weight concrete has been produced using oil palm shells [3] and demolished masonry waste [4] as aggregates. An improvement in the modulus of elasticity of concrete was observed. with partial replacement of crushed stone coarse aggregate by crushed vitrified soil aggregate [5].

Compressive strength and abrasion resistance were increased when crushed ceramic waste was used to partially replace conventional gravel coarse aggregate [6]. On the other hand, De Brito et al [7] 
found that strength decreases as the quantity of ceramic aggregates in concrete increases and the decrease in compressive strength is higher than that in the flexural strength. While, the abrasion resistance of concrete made with ceramic recycled aggregates is higher than that of concrete made with limestone aggregates. Durability of cementatious materials like mortar and concrete is as important as compressive strength.

In recent publisned work by the author and coworkers [8], lead slag extracted from recycling of the spent batteries in the homely workshops was used as concrete aggregate. Short term mechanical properties, wear resistance and radiation absorption were studied. In the same year, Penpolcheroen [9] published the second contribution in the use of secondary lead slag as a construction material. He found that all samples exhibited higher compressive strengths than that of the sample without slag, which increased with increasing the slag contents and ages. The highest compressive strength was found for the sample containing $20 \%$ slag as cement replacement and $100 \%$ slag as aggregate replacement.

The results of chemical analysis of the used lead slag in the previous work $[8,9]$ revealed that the oxide components of the slag were similar to those of ordinary Portland cement (OPC). For environmental concen, leachability of lead (Pb) from all samples was also carried out [9] on samples with high slag content. The amounts detected were much lower than the acceptable limit $(5 \mathrm{ppm})$ for the requirement of Thai hazardous waste disposal standard. So, the application of the slag for construction material is fully attractive. The environmental conditions such as temperature, humidity and the mechanism of chemical transports are the major factors causing chemical and physical attacks [10]. Thus, the performance of construction materials fabricated from slag under these conditions is of primary important. So, in the present work, the effect of high temperature on the compressive strength and abrasion resistance of mortar made with lead slag as partial replacement of sand was studied.

\section{EXPERIMENTAL WORK}

All materiais used in this study were locally available materials. The cement used was type I ordinary Portland cement. The sand was siliceous sand with $100 \%$ passing ASTM sieve No. 4 . The fine lead-slag (FLS) used in this research was obtained by recycling of the spent batteries electrodes in homely workshops. Recycled- lead slag (RLS) was used as fine aggregate in mortar manufacture. The RLS was crushed to the desired gradation by using a roller mill. An energy dispersive X-ray spectroscope was performed to analyze the chemical compositions of the materials. The results of chernical analysis of the used FLS and OPC are given in Table 1. The physical and mechanical properties of the used fine aggregate (sand and FLS) are given in Table 2 . Mixing water was clcan tap water free from impurities and organic matters. The sand: cement ratio was $3: 1$ by weight and the water cement ratio was 0.5 . The total fine aggregates (TFA) in the mix were partially replaced by FLS particles. The percentages by volume of FLS/TFA were $0,10 \%$, $20 \%, 30 \%$, and $40 \%$.

Table 1 Chemical composition of FLS and OPC

\begin{tabular}{|c|c|c|}
\hline Constituent & FLS $(w t \%)$ & OPC $(w t \%)$ \\
\hline $\mathrm{CaO}$ & 2.5 & 62 \\
\hline $\mathrm{SiO}_{2}$ & 12.98 & 20.39 \\
\hline $\mathrm{Al}_{2} \mathrm{O}_{3}$ & - & 5.05 \\
\hline Iron oxide & $\begin{array}{c}72.8 \\
\text { as } \mathrm{Fe}_{3} \mathrm{O}_{4}\end{array}$ & $\begin{array}{r}2.89 \\
\text { as } \mathrm{Fe}_{2} \mathrm{O}_{3}\end{array}$ \\
\hline $\mathrm{MgO}$ & 0.26 & 2.07 \\
\hline $\mathrm{K}_{2} \mathrm{O}$ & 0.21 & 0.5 \\
\hline $\mathrm{Na}_{2} \mathrm{O}$ & 0.53 & 0.07 \\
\hline $\mathrm{SO}_{3}$ & $=$ & 2.4 \\
\hline $\mathrm{MnO}$ & 0.46 & - \\
\hline $\mathrm{Pb}$ & 4.1 & $=$ \\
\hline Others & 2.33 & 1.53 \\
\hline L.O.I & 3.83 & 3.1 \\
\hline
\end{tabular}

Table 2 Physical properties of sand and FLS

\begin{tabular}{|c|c|c|}
\hline Property & Sand & FLS \\
\hline Specific gravity & 2.45 & 4.28 \\
\hline \multicolumn{3}{|l|}{ Density, $\mathrm{kg} / \mathrm{m}^{3}$} \\
\hline Loose & 1610 & 2280 \\
\hline Dense & 1700 & 2820 \\
\hline \multicolumn{3}{|l|}{$\%$ Voids } \\
\hline Loose & $38 \%$ & $47 \%$ \\
\hline Dense & $27 \%$ & $34 \%$ \\
\hline$\%$ Water absorption & 0.42 & 3.95 \\
\hline $\mathrm{FM}$ & 2.55 & 3.35 \\
\hline
\end{tabular}

Batch materials required for casting twenty one cubes (70 mm side length) for compression test and twenty one cylinders (25 mm diameter and $25 \mathrm{~mm}$ height) for abrasive wear test were weighted first. Dry materials for this batch were mixed in the dry state for a time to insure the homogeneity of the mixture before adding the mixing water. The test specimens were removed from the moulds 24 hours after casting and immediately submersed in the curing water for 28 days. A total number of 105 compression specimens and 105 abrasion specimens representing five mixes having different FLS/TFA\% were tested.

The experimental program suggested for the present work included the exposure of the mortar specimens 


\section{H. Seleem, "Strength and Abrasion Resistance of Recycled Lead Slag Mortar At High Temperatures"}

to different target temperatures (TT) ranging from $200^{\circ} \mathrm{C}$ to $700^{\circ} \mathrm{C}$ step $100^{\circ} \mathrm{C}$ at an average heating rate of about $10^{\circ} \mathrm{C} / \mathrm{min}$. An electric furnace of $1600^{\circ} \mathrm{C}$ maximum temperature was used. The specimens were placed inside the furnace and the temperature was raised until it reaches the desired target temperature. The specimens were sustained at this target temperature for 2 hours. Affer that they allowed to cool outside the furnace at room temperature (residual unstressed test sequence), Fig. 1. All cubes specimens were weighted before and after heating to calculate the mass loss due to heating.

A universal-testing machine of $1000 \mathrm{kN}$ maximum capacity was used for the compression test. Among test methods suggested by ASTM for the estimation of the wear resistance of cementitious materials, the revolving disk. (ASTM C779, Procedure A) test method [11] was selected. An aggregate abrasion testing machine (Cat.' No. EL 42-500) was used to perform the test. The test specimens were exposed to abrasive standard sand, passed from $0.6 \mathrm{~mm}$ sieve and retained on $0.45 \mathrm{~mm}$ sieve, for 500 revolutions under a load of $750 \mathrm{gm}$. Each specimen was weighted before and after the test and the weight loss was calculated.
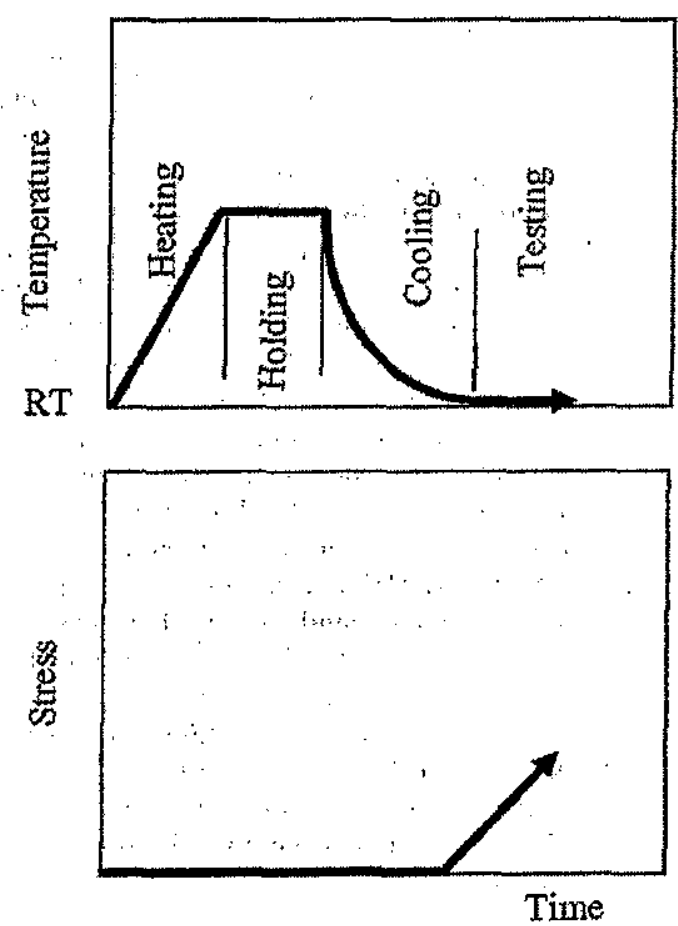

Fig. 1 Sequence of residual unstressed test followed in this work

\section{RESULTS AND DISCUSSIONS}

\section{Density}

The effect of FLS/TFA \% on the relative density of mortar is illustrated in Fig. 2. The relative density is the ratio of the density of mortar specimen with sand replaced by FLS to that of $100 \%$ sand specimen. The addition of FLS to mortar results in a linear increase in the density of the material to reach $20 \%$ higher than that of $100 \%$ sand at FLS/TFA $\%$ equal to $40 \%$.

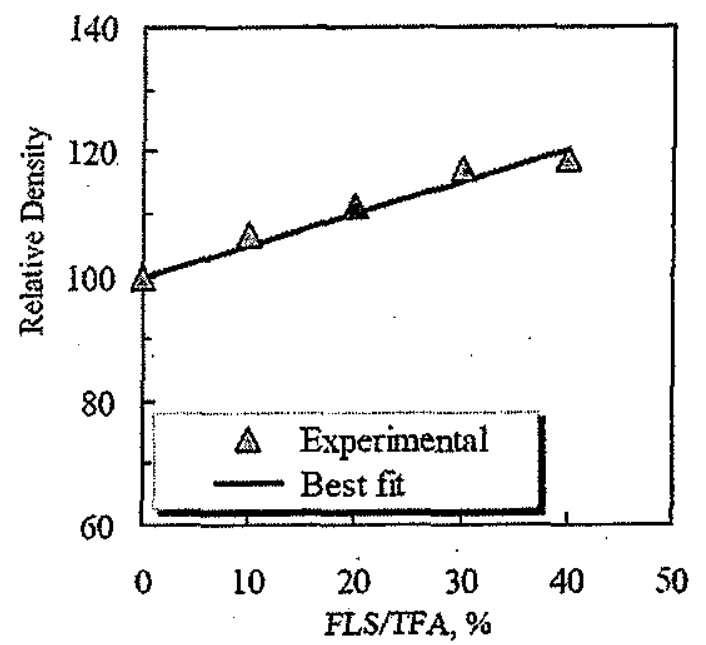

Fig. 2 Effect of FLS/TFA \% on the hardened density of concrete mortar.

\section{Mass Loss}

The mass losses for the different mortar specimens due to water evaporation as a result of exposure to high temperatures are shown in Fig. 3 for the different FLS/TFA \%. The relative mass losses were estimated as the difference in the mass between the unheated and heated specimens to that of the unheated specimens. An increase in the relative mass loss was observed for all mixtures with increasing temperature. The loss rate is high at low temperatures up to $300^{\circ} \mathrm{C}$, after that it stabilized before increasing again above $500^{\circ} \mathrm{C}$. Similar behavior was observed for concrete specimens but the stabilized stage was ranged between $200^{\circ} \mathrm{C}$ and $400^{\circ} \mathrm{C}$ [12]. It is also clear that the mix of FLS/TFA equal to $10 \%$ showed the highest relative mass loss, while that of $40 \%$ FLS recorded the lowest relative mass loss. The mass loss at low temperatures, below $300^{\circ} \mathrm{C}$, is caused by quick evaporation of capillary water. Over $400^{\circ} \mathrm{C}$, the mass loss is caused by evaporation of chemically combined water (dehydration) and decomposition [13]. Above temperature of $500^{\circ} \mathrm{C}$, the dehydration of the chemically combined water of the hydrated Calcium Silicate Hydrate (CSH) resulting in unhydrated products was accompanied by observable mass loss. 


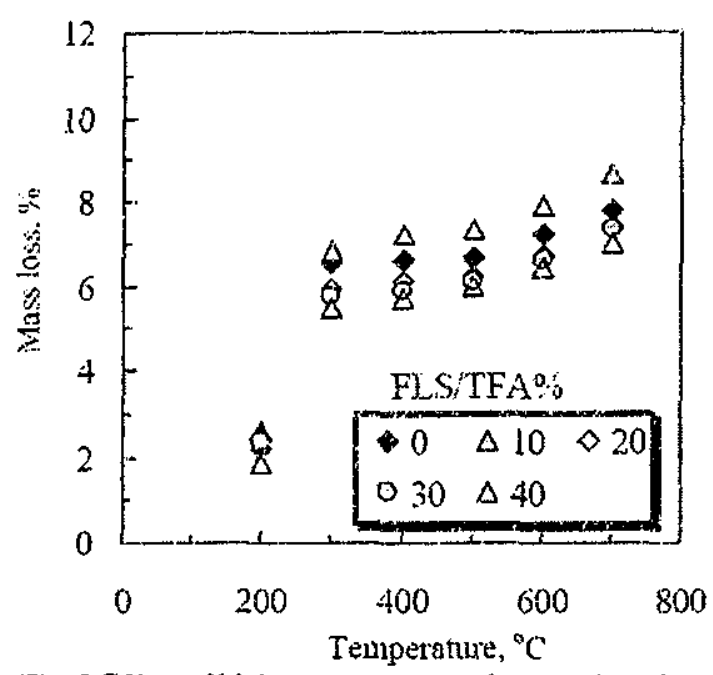

Fig. 3 Effect of high temperature on the mass loss for different FLS/TFA \%.

\section{Compressive Strength}

The effect of high temperature on the relative compressive strength of mortar specimens with FLS/TFA equal to $0 \%, 10 \%, 20 \%, 30 \%$ ard $40 \%$ is shown in Fig. 4. The relative compressive strength here is defined as follows:

Relative compressive strength $=\left[\sigma_{\mathrm{cHT}} / \sigma_{\mathrm{cRT}}\right] \times 100$

Where $\sigma_{\mathrm{cHT}}$ is the compressive strength of the specimen exposed to the desired target temperature and $\sigma_{\mathrm{CRT}}$ is the corresponding compressive strength of the unheated specimens at the same FLS $/ \mathrm{TFA} \%$. The general trend for the different FIS/TFA \% is similar, i.e. with increasing the target temperature, a steady state drop in the relative strength is observed up to a temperature of $500^{\circ} \mathrm{C}$, where the average relative strength is about $83 \%$. After $500^{\circ} \mathrm{C}$, the average relative strength dropped suddenly to reach $51 \%$ with increasing temperature to $600^{\circ} \mathrm{C}$. At $700^{\circ} \mathrm{C}$, the relative strength reached an average of $36 \%$. At temperature of $200^{\circ} \mathrm{C}$, the average relative strength is $96 \%$. In a previous work by the author and coworkers [12] on the effect of high temperature on the relative strength of concrete, a sudden drop was recorded in the strength after $200^{\circ} \mathrm{C}$ and gravel concrete completely lost its strength at $600^{\circ} \mathrm{C}$. The absence of coarse aggregate in the mortar decreased the effect of differential thermal expansion that occurred between cement paste and aggregate. This can explain the slow gradual decrease in the relative strength at temperature up to $500^{\circ} \mathrm{C}$. The high relative strength at $200^{\circ} \mathrm{C}$ is attributed to the enforced hydration process due to water evaporation [14]. The structure of the cement mortar after high temperature exposure gets loose because of the pore expansion owing to the vaporization of the absorbed water. The loss of water from the free calcium hydroxide (CH) (results from cement hyuration), leaving calcium oxide (quick îme). This calcium oxide absorbs water from the surrounded atmosphere as the specimen leaved cool. Thus it re-hydrated to $\mathrm{CH}$ or reacts with atmospheric $\mathrm{CO}_{2}$ resulting in calcium carbonate $\left(\mathrm{CaCO}_{3}\right)$. Theses processes are accompanied by an expansion in the volume, which may disrupt the material $[13,15]$.

To explain the role of FLS/TFA $\%$ on controlling the behavior of mortar at high temperature, the compressive strength of the heated mortar specimen with different FLS/TFA\% $\left(\sigma_{c}\right)$ was divided to that with FLS/TFA\% equal to $0\left(\sigma_{c o}\right)$ at the different regimes of high temperatures including $\mathrm{RT}$ as shown in Fig. 5. The effect of FLS/TFA\% at different temperatures shows sımilar trends, i.e. an increase in the strength ratio as the FLS/TFA\% increases up to FLS/TFA $=20 \%$ and after that it decreases to approach that at $0 \%$ FLS/TFA at FLS/TFA \% equal to $40 \%$. Also it is clear that the strength ratio increases as the exposed temperature increases especially at temperatures of 600 and $700^{\circ} \mathrm{C}$ for all FLS/TFA \%. As an example for FLS/TFA $\%$ equal to $20 \%$, the strength ratio reached 1.12 at $200^{\circ} \mathrm{C}, 1.18$ at $500^{\circ} \mathrm{C}$ and 1.60 at $700^{\circ} \mathrm{C}$. The FLS shows some of hydration reactivity, which allows it to behave as a pozzolanic when it was mixed with cement. So, using of leadslag as aggregate enhances a type of aggregate cement paste interface. The decrease in the strength with further increase in the replacement of sand by FLS may be due to the fact that by increasing the fine lead-slag aggregate without the equivalent required amount of cement to achieve pozzolanic hydration, an adverse effect on the bond in the matrix is occurred [9]. At high temperatures, the reduced amount of $\mathrm{Ca}(\mathrm{OH}) 2$ due to the pozzolanic effect of FLS increase the strength ratio at those temperatures, which otherwise results in strength loss and disintegration [16]. Photo.1 shows the crack pattem of the mortar specimens after exposed to temperature of $700^{\circ} \mathrm{C}$ for FLS/TFA equal to 0 and $20 \%$. A wide crack is observed on the specimen surface for FLS/TFA\% equal to 0 compared to a very narrow surface cracks in the case of FI.S/TFA equal to $20 \%$. 
M. H. Seleem, "Strength and Abrasion Resistance of Recycled Lead Slag Mortar At High Temperatures"
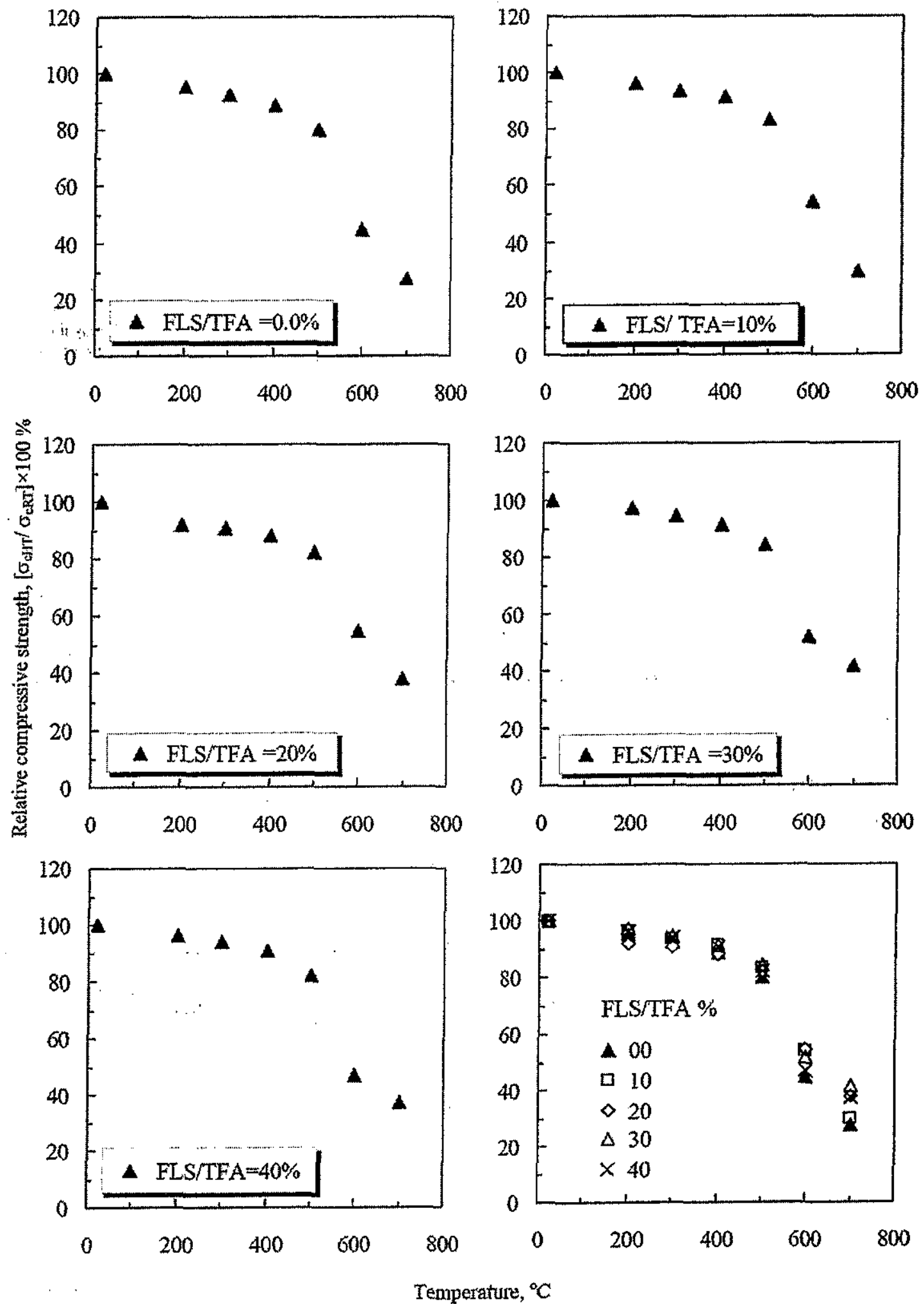

Fig. 4 Relative compressive strength against temperatures for different FLS/TFA\%. 

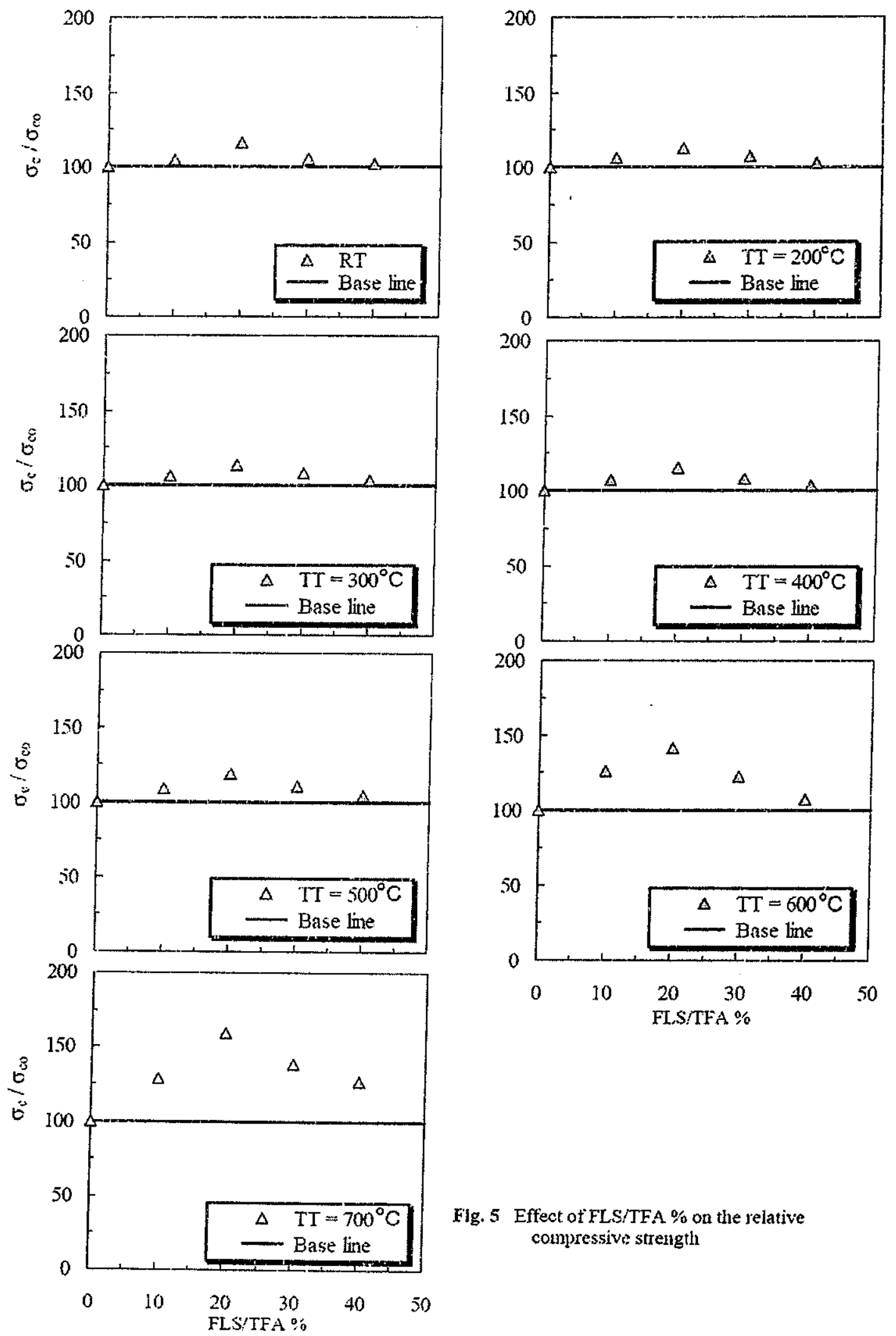

Fig. 5 Effect of FLS/TFA \% on the relative compressive strength 

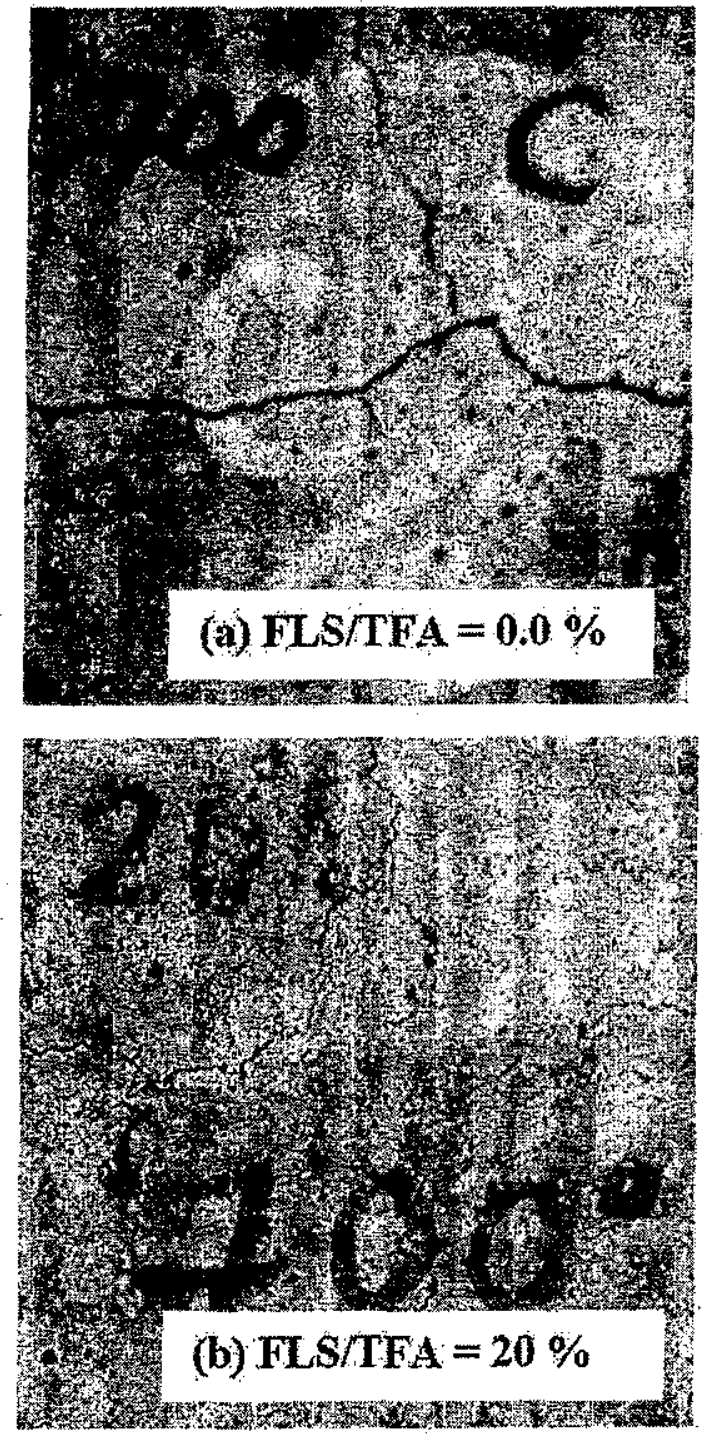

Photo. 1 Crack pattern of mortar specimens after heating to $700 \circ \mathrm{C}$ for

a) FLS/TFA $=0.0 \%$ and

b) $\mathrm{FLS} / \mathrm{TFA}=20 \%$.

\section{Abrasion Resistance}

The effect of high temperature on the abrasion resistance of mortar fabricated by partial replacement of sand by different percentages of FLS/TFA is shown in Fig. 6. The abrasion resistance defined by the wear rate (WR) is expressed as the weight loss of the tested specimen divided by the area of the surface exposed to wear. This is of a physical meaning, since abrasion is a surface property that defines surface layer characteristics. The exposed surface area for all specimens is constant and equal to the area of a circle having a diameter of $25 \mathrm{~mm}$. The unit now is $\mathrm{gm} / \mathrm{mm}^{2}$. Fig. 6 shows the relation between the relative wear rate (wear rate of specimens exposed to heat multiplied by 100 and divided by that of the unheated specimens at the same FLS/TFA\%). The figure shows increases in the relative wear rate with increasing temperature for all FLS/TFA\%. This means a decrease in the abrasion resistance with increasing temperature and the relation is approximately linear. This trend is similar to that of compressive strength.

To reflect the effect of FLS/TFA\% of the abrasion resistance of mortar at different temperature, the wear rate ratio (the ratio of the wear rate of mortar specimen containing FLS to that of $100 \%$ sand at the same temperature) is drawn in Fig. 7 against FLS/TFA\% for different temperatures considered. The presence of FLS enhances the abrasion resistance of mortar specimens up to $20 \%$ replacement and after that the effect decreases until it approximately match that of $100 \%$ sand at FLS/TFA equal to $40 \%$. The role of FLS replacement is more pronounced at high temperatures above $500^{\circ} \mathrm{C}$.

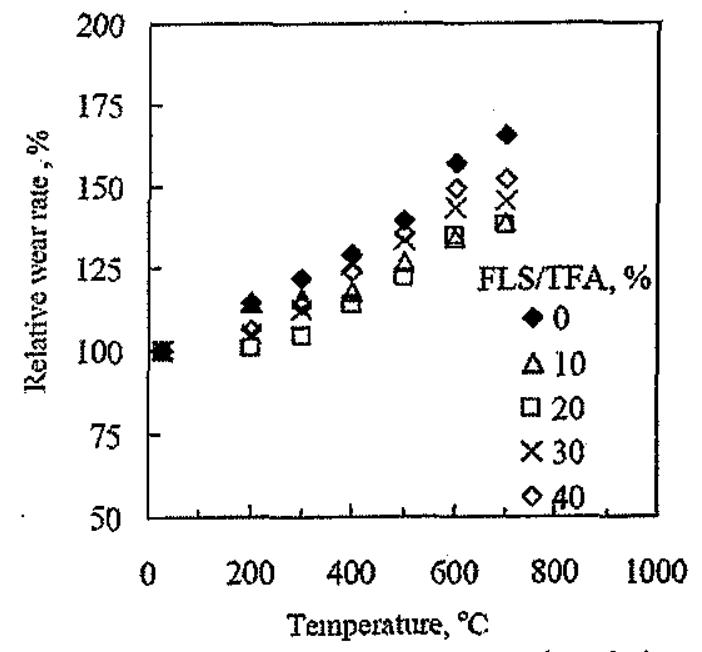

Fig. 6 Effect of high temperature on the relative abrasion rate for different FLS/TFA \%.

The presence of FLS, which behaves as a pozzolanic material reacts with the hydration products forming and thus enhances cement aggregate interface and leads to dense structure composed of irregular grains and hydrated products attach to the aggregate surface strongly. This improves the resistance of the mortar to abrasive wear. With the increase in FLS above $20 \%$, the remaining un-reacted FLS behaves as filler and which can easy leave the surface of the specimen during abrasion. 


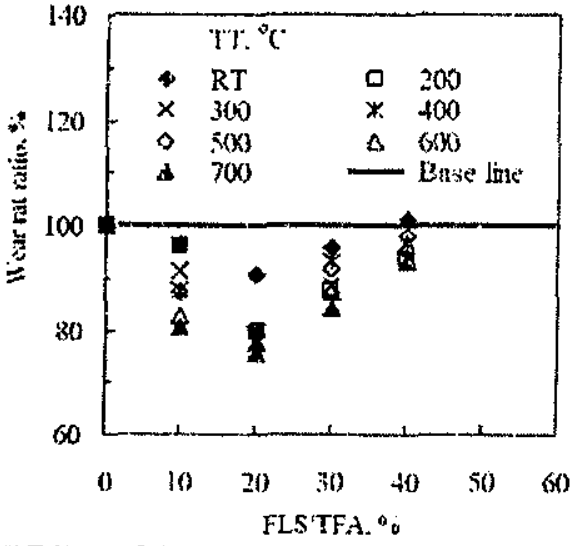

Fig. 7 Effect of FLS/TFA \% on the wear rate ratio at different high temperatures.

\section{CONCLUSIONS}

1. The compressive strength of fine lead slag mortar decreased gradually with increasing temperature up $500^{\circ} \mathrm{C}$ and after that temperature the strength decreased narkedly.

2. With increasing fine lead slag percent as a partial replacement of sand, the compressive strength increased up to fine lead slag percent of $20 \%$ and after that it decreases but still higher than that of $100 \%$ sand at $40 \%$ fine lead slag.

3. The presence of fine lead slag played a vital role in enhancing the strength ratio of lead slag mortar compared to those of sand mortar especially at high temperatures above $500 \mathrm{aC}$.

4. The abrasion resistance of plain and lead siag mortar decreased linearly with increasing high temperature.

5. The highest abrasion resistance was that of moxtar specimens of $20 \%$ fine lead slag.

6. The presence of fine lead slag enhanced the abrasion resistance of plain mortar and the rate of enhancement is more pronounced at temperatures above $5000 \mathrm{C}$.

\section{REFEREIUCES}

[1] Jepsen, M. T., Mathiesen, D., Munch-Petersen, C., Bager, D., (2001), Durability of resource saving "Green" type of concrere, In: Proceedings of FIB - Symposium on concrete and environment, Berlin.

[2] Monce, N. and Ashfaq, K., (2001), Cementitious composites containing recycled tire rubber: an overview of engineering properties and potentia? applications, Cement Concrete Aggregate, Vol. 23, pp. 3-10.

[3] Basri, H. B., Mannan, M. A., Zain, M. F. M., (1999), Concrate using waste oil palm shells as aggregate, Cement Concrete Research, Vol. 29, pp. 619-22.

[4] Padmini, A. K, Ramamurthy, K., Mathews, M. S., (2001), Behaviour of concrete with low-strength bricks as lightweight coarse aggregate, Magazine of Concrete Research, Vol. 53, pp. 367-375.

[5] Palmquist, S. M., Jansen, D. C., Swan, C. W., (2001), Compressive behavior of concrete with vitrified soil aggregate, ASCE J. Mater. Civil Eng., Vol. 13, pp. 389-394.

[6] Binici, H., (2007), Effect of crushed ceramic and basaltic pumice as fine aggregates on concrete mortars properties, Construction and Building Materials, Vol. 21, pp. 119i-119\%.

[7] De Brito, J., Pereira, A. S., Correia, J. R. (2005), Mechanical behaviour of non-structural concrete made with recycled ceramic aggregates, Cement \& Concrete Composites, Vol. 27, pp. 429-433.

[8] Metwally, M. E. A, Seleem, M. H., Balaha, M. M., and Abd El-Rahman, H. (2005), Utilization of slag produced from recycling of spent lead-batteries as concrete aggregate, Alexandria Engineering Journal, Vol. 44, pp. 883-892.

[9] Penpolcharoen, M. (2005) Utilization of secondary lead slag as construction material, Cement and Concrete Research, Vol. 35, pp. 1050-1055

[10] Bilirb, İ. Y. T, and Özkanc, Ö., (2007), Durability of concrete incorporating non-ground blast furnace slag and bottom ash as tine aggregate . Building and Environment, Vol. 42, pp. 26512659.

[11] American Society for Testing and Materials, (1989) "Test method for abrasion resistance of horizontal concrete surfaces", ASTM C779-89, Annual Book of ASTM Standard, ASTM, 4.02, p 359.

[12] El-Shihy, A. M., Seleen, M. H., Shoaib, M. M. Badawy, A. A. M, and Gabal, A. E. K. (2004) Effect of elevated temperatures on the mechanical and physico-chemical behavior of normal, high strength and light weight concrete. Mansoura $4^{\text {th }}$ Int. Engineering Conf,. 20-22 April, C51-C59.

[13] Hewlett, P. C., (1998), Lea's chemistry of cement and concrete. Co-published in North Central and South America by Jhon Wiely \& Sons Inc., New York and Toronto, $4^{\text {th }}$ edition.

[14] Zang, B., Bicanic, N., Pearce, C. J. and Balabanis, G. (2000), Residual fracture properties of normal and high-strength concrete subjected to elevated temperature. Magazine of Concrete Research, Vol. 52, No.2, pp. 123-136.

[15] Wei-Ming Lin, Lin, T. D. and Powers-Couche, (1996), Microstructures of fire-damaged concrete. ACI, Material Journal, Vol. 93, No. 1, pp. 199-205.

[16] Chan, S. Y. N. Peng, G. F., Anson, M., (1999) Residual strength and porestructure of highstrength concrete and normal-strength concrete after exposure to high temperatures, Cement \&. Concrete. Composite, Vol. 21, pp. 23-27. 